\title{
Development of Drone Cargo Bay with Real-Time Temperature Control
}

\author{
Sedam Lee, Yongjin Kwon* \\ Department of Industrial Engineering, College of Engineering, Ajou University, Suwon, South Korea \\ Email: *yk73@ajou.ac.kr
}

How to cite this paper: Lee, S. and Kwon, Y. (2019) Development of Drone Cargo Bay with Real-Time Temperature Control. World Journal of Engineering and Technology, 7, 612-621. https://doi.org/10.4236/wjet.2019.74044

Received: October 10, 2019

Accepted: November 1, 2019

Published: November 4, 2019

Copyright (c) 2019 by author(s) and Scientific Research Publishing Inc. This work is licensed under the Creative Commons Attribution International License (CC BY 4.0).

http://creativecommons.org/licenses/by/4.0/ (c) (i) Open Access

\begin{abstract}
In order to deliver medical products (medicines, vaccines, blood packs, etc.) in time for needed areas, a method of transporting goods using drones is being studied. However, temperature-sensitive medical products may decay due to outside temperature changes. The time required to transport over the distance may vary a lot as well. As a result, the likelihood of the goods deteriorating is very high. There is a need for a study on cargo bay to prevent this and to protect the medical goods. In this paper, in order to protect the temperature sensitive medical goods, the inside cargo bay is equipped with the cooling fan device and the electric heating elements. These elements can be monitored and controlled according to the user's discretion. By using the web server built inside the cloud server, the temperature can be controlled in real-time from anywhere without the limitation of distance. We built the proposed device, and installed it on the drone cargo bay. The test results show that the cargo bay can be temperature-controlled, and the setting can be maintained over a great distance. The user can watch the temperature variations during the transport and ascertain the goodness of the medical supply with the data. It is expected that such development can greatly enhance the utility of the drone operations, especially for the medical supply transport applications.
\end{abstract}

\section{Keywords}

Real-Time Control, Cargo Bay Temperature, Cloud Server, Medial Transport, Drones

\section{Introduction}

In many countries around the world, a fair accessibility to roads varies according to the geographic characteristics and weather conditions. As a result, it is diffi- 
cult to transport items, such as medical supplies (medicines, vaccines, blood packs, etc.) when needed [1]. Currently, there is a variety of methods for transporting medical products by walking, transporting vehicles, helicopters, and airplanes. However, these methods have limitations in terms of distance, road accessibility, delivery costs, and geographic conditions [1]. To overcome these limitations, methods for transporting medical products using drones are being studied. The use of drones among various methods has already been extended to many industries [2] [3]. In addition, the transport of goods using drones has been steadily studied in recent years [4]. According to the papers that studied the effects of transporting blood by drones, the use of unmanned aircraft does not affect the quality of the products, such as coagulation and deterioration of medicines and biochemical samples [5]. However, the factor mostly affecting the goods in transport is the external environment. Depending on various factors such as region, season and weather, medical and various items stored in drone cargo bay may deteriorate. Therefore, there is a need for a method for protecting the medical supplies from outside temperature changes.

Currently, a common method for lowering the temperature inside the drone cargo bay is by arranging dry ice, and ice packs. Those include the Rwanda's blood transport drone operations and a few other countries. This method does not have a means to raise or control the internal temperature to the desired setting. The existing method is simple, but due to various external requirements, it is difficult to avoid deterioration of stored items. This is because the type, place, time, and storage temperature of the stored items are all different. For this reason, there is a need for a method capable of controlling the cargo bay temperature. To solve this problem, we developed a technology to control the temperature inside the drone cargo bay in real-time. The structure of this paper shows Chapter 2 as related works, the configuration of temperature control system in Chapter 3, and hardware development in Chapter 4. Chapter 5 describes software development, and Chapter 6 describes the prototyping results. Finally, the last chapter includes concluding remarks.

\section{Related Works}

In recent years, various approaches have been proposed for the delivery of medical items (blood, medical supplies, defibrillators, life-rings, etc.) using the drones [5]. One of these methods is to develop an efficient delivery system to overcome the hurdles from mountains and buildings during the flight, or to operate and manage drones using a modular design approach to effectively accommodate the various cargo types [6] [7]. However, the methods proposed or introduced in the papers have not considered the goodness of the transport items during the flight. In addition, the paper for improving the goodness of transport items is mainly dealt with cargo bay insulation to maintain the internal temperature. In most cases, the method focuses on maintaining a low temperature. It shows no result about transporting items that need to be stored at high temperature. It is difficult to find the related study that shows the flexible tem- 
perature control of the drone cargo bay [8] [9]. In this regard, the method to control the temperature of cargo bay by raising or lowering the temperature remotely can be viewed as quite innovative [10] [11].

\section{Configuration of Temperature Control System}

In order to operate cargo bay module with real-time temperature control, the system is configured as in Figure 1. System configuration is divided into hardware and software sections. Hardware is composed of the cargo bay control module that exchanges data with the database, mainly on Raspberry Pi. This controller controls the attached devices and sensors. Software is largely divided into cloud server and web browser. Client and database that can send and receive data to and from the cloud server are configured. The data can be transmitted to the UI (user interface) of web browser through terminal. The real-time temperature control method proposed in this study is the method of building various servers for network connectivity through cloud sever, and controlling the cargo bay module using the deployed server, which can check and command the data of the cargo bay module using the UI.

\section{Hardware Design}

The temperature-controlled drone cargo bay proposed in this study is $730-\mathrm{mm}$

Temperature Control System Configuration

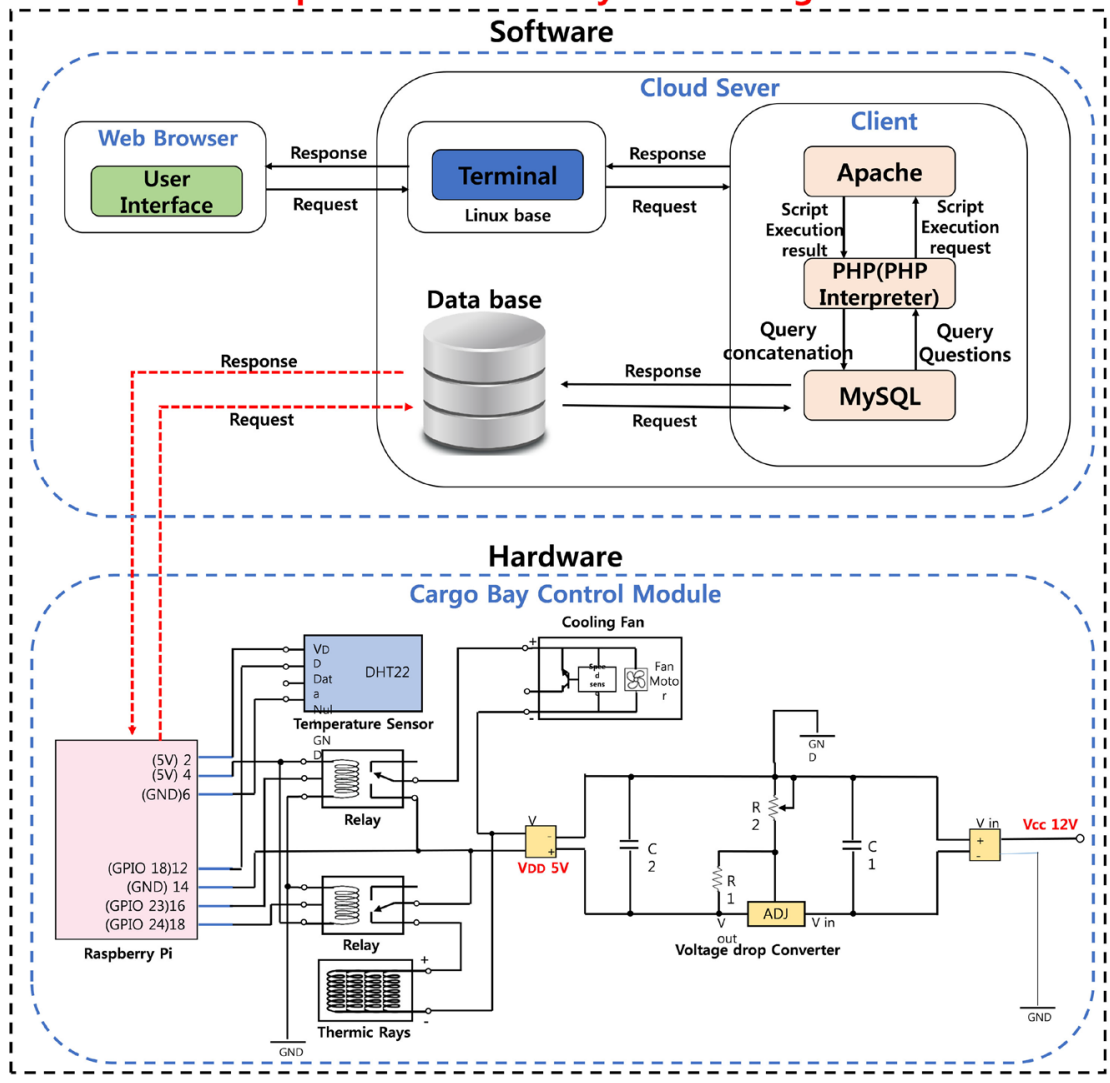

Figure 1. Temperature control module system configuration. 
wide, 250-mm long and 200-mm high, as shown in Figure 2. This is designed by considering the payload restrictions of the drone. In order to effectively lower the internal temperature during the flight, the air circulation port was fabricated. The cooling fan plays the role of taking the air to the cargo bay, which can lower the internal temperature. Thermic ray, which generates heat through the electricity supply, was used, and a barrier membrane was designed to maintain the cargo bay temperature efficiently. The barrier membrane also divided the cargo bay interior space into an interior compartment for storing goods and an exterior compartment for installing temperature control devices. Table 1 and Table 2 show the details.

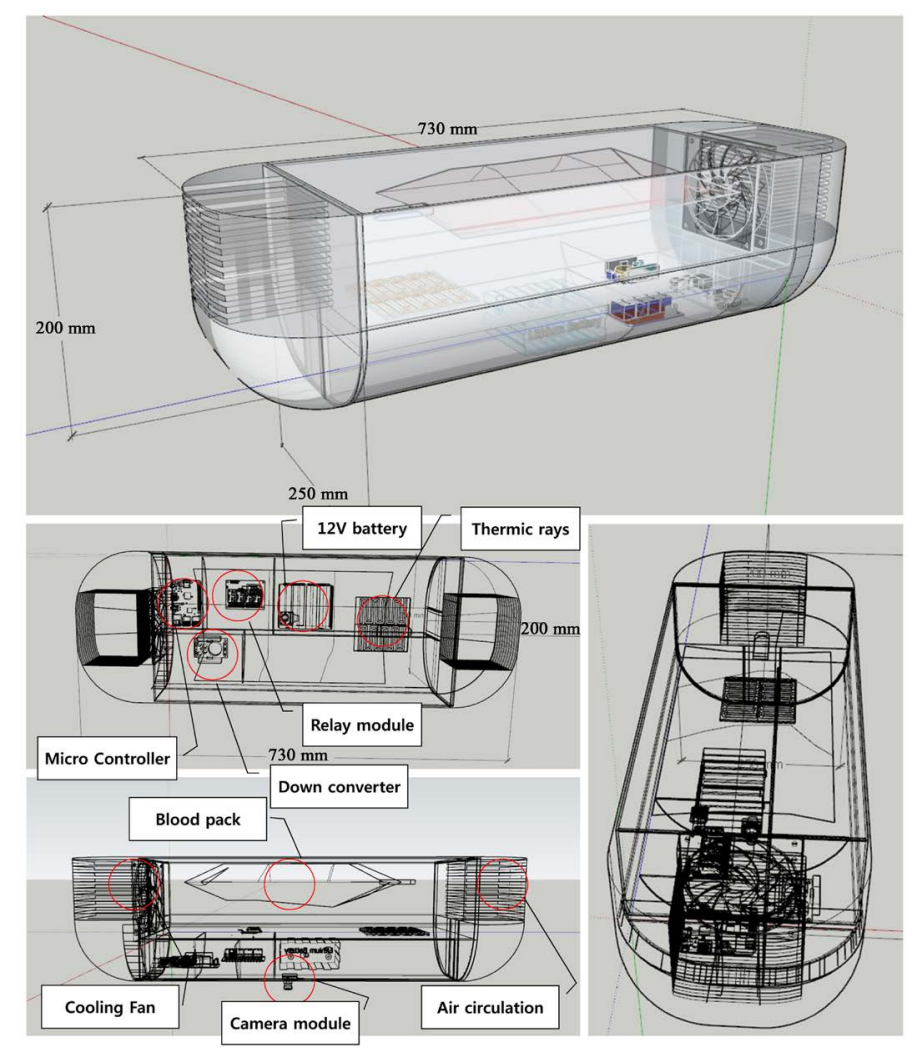

Figure 2. Temperature controlled cargo bay schematic.

Table 1. Controller specification.

\begin{tabular}{|c|c|}
\hline Detail & Raspberry Pi 3 b+ \\
\hline Processor & - Broadcom BCM2837B0, Cortex-A53 64-bit \\
\hline Memory & - 1 GB LPDDR2 SDRAM \\
\hline Connectivity & $\begin{array}{l}\text { - Dual band } 2.4 \mathrm{GHz} \& 5 \mathrm{GHz} 802.11 \mathrm{~b} / \mathrm{g} / \mathrm{n} / \mathrm{ac} \\
\text { - } \quad \text { Gigabyte Ethernet over USB } 2.0\end{array}$ \\
\hline Access & - Extended 40-pin GPIO header \\
\hline Input Power & $\begin{array}{l}-\quad 5 \mathrm{~V} / 2.5 \mathrm{~A} \text { DC via micro USB connector } \\
-\quad 5 \mathrm{~V} \mathrm{DC} \text { via GPIO header }\end{array}$ \\
\hline Environment & - Operating temperature, $0^{\circ} \mathrm{C}-50^{\circ} \mathrm{C}$ \\
\hline
\end{tabular}


Table 2. Temperature sensor, thermic rays, cooling fan specifications.

\begin{tabular}{cccc}
\hline Detail & DHT22 (sensor) & Themic rasys & Cooling fan \\
\hline Input Power & DC $3.3 \mathrm{~V}-5 \mathrm{~V}$ & DC $5 \mathrm{~V} / 570 \mathrm{~mA}$ & DC $12 \mathrm{~V} / 0.5 \mathrm{~A}$ \\
Measuring range & $-40^{\circ} \mathrm{C}-80^{\circ} \mathrm{C}$ & $\sim 200^{\circ} \mathrm{C}$ & - \\
accuracy & $\pm 0.5^{\circ} \mathrm{C}$ & - & - \\
Size & $43 * 26^{\star} 18(\mathrm{~mm})$ & $90 * 60 * 0.3(\mathrm{~mm})$ & $97 * 97 * 33(\mathrm{~mm})$ \\
Weight & $9.3 \mathrm{~g}$ & $15 \mathrm{~g}\left({ }^{*} 2\right)$ & $155 \mathrm{~g}$ \\
\hline
\end{tabular}

\section{Software Design}

\subsection{Network Connection}

It is implemented that a communication using RF sensor as a way to check and control the temperature inside cargo bay in real time [12]. However, RF communications have adopted a network connection method to address distance constraints. A network connection using a specific IP address by building a web server in the controller's memory is not possible due to the nature of the drone when the network is disconnected due to geographic distances. Therefore, we designed a static IP that plays an intermediate bridge role by building a web server through a cloud server. The web server was installed using "Apache, PHP, MYSQL" on the cloud server, and data were running with the use of interlocks to receive data from the controller and send commands. Table 3 shows the data interlocking list for network connections. All six data linkage lists are implemented in PHP language through Terminal. It is designed to display and command data on the UI through interlocked data.

The control UI is designed to prevent users from receiving unnecessary information through the controller's kernel window or complicating the controller's command statements. It is designed to receive the necessary information quickly or issue commands. The first box of each configuration in Figure 3 shows the current temperature, as well as the upper and lower limits of the temperature. The second is the upper and lower limit input fields of temperature. The third is the operating status of thermic ray and cooling fan, and the on/off control switch of the controller power. The fourth box is a graph showing the cargo bay's internal temperature change, updated continuously over time to show the changes in temperature.

\subsection{Control Algorithm Design}

The goods stored in cargo bay for the transport have different storage temperatures. Since the different storage temperatures must be considered for each item, the cargo bay internal temperature must be freely set. When a certain value is set for internal temperature control and there is no margin value of the specified temperature, the temperature control device adjusts frequently even with a minor temperature change of only $0.1^{\circ} \mathrm{C}$. Therefore, the temperature should be set by specifying the range. In this study, the method of setting and controlling the temperature using upper and lower limits was used. 


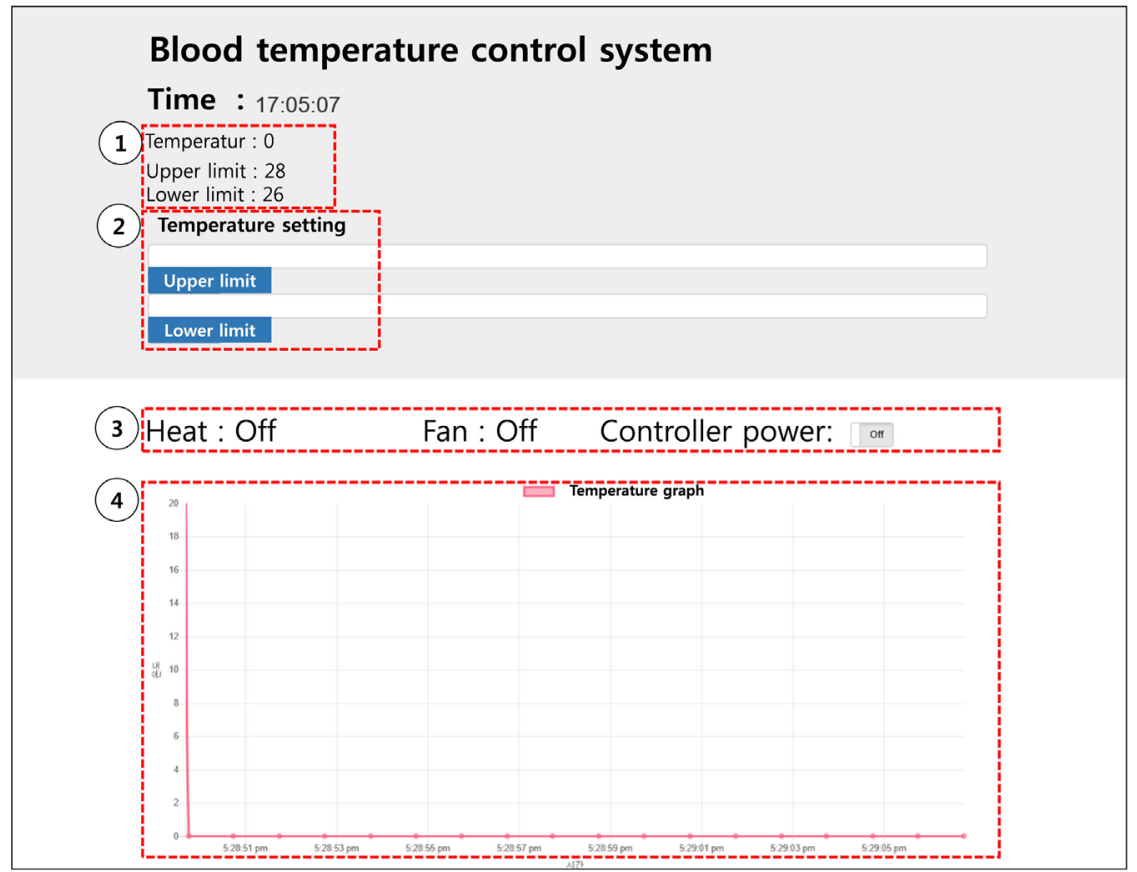

Figure 3. Temperature control user interface.

Table 3. Network data interlock list.

\begin{tabular}{|c|c|}
\hline Division & Contents \\
\hline Temperature sensor value & $\begin{array}{l}\text { - Data value measured by temperature sensor is saved in database } \\
\text { - Keep } 50 \text { latest data and delete old data }\end{array}$ \\
\hline UI data value & $\begin{array}{l}\text { - Database and UI interworking, output values stored in database } \\
\text { - } \quad \text { Retrieve sensor value from database every second }\end{array}$ \\
\hline Cooling fan & $\begin{array}{l}\text { - According to the upper and lower limits of the set temperature, } \\
\text { whether or not operation is carried out to or from the database }\end{array}$ \\
\hline Thermic rays & $\begin{array}{l}\text { According to the upper and lower limits of the set temperature, } \\
\text { whether or not operation is carried out to or from the database }\end{array}$ \\
\hline Micro Controller & $\begin{array}{l}\text { - Pass the data value collected from the Micro Controller } \\
\text { - Passing device values controlled through the controller } \\
\text { to the database }\end{array}$ \\
\hline User input value & $\begin{array}{l}\text { - Input the input value that user wants to control to } \\
\text { UI and pass to database }\end{array}$ \\
\hline
\end{tabular}

The temperature control algorithm set the basic operation of the thermal ray and cooling fan to zero as shown in Figure 4. After that, the upper and lower limit values are entered and the algorithm is repeated or terminated according to each condition. For example, in order to store an article having a storage temperature of $25^{\circ} \mathrm{C}$ to $26^{\circ} \mathrm{C}$, the upper limit value is set to $26^{\circ} \mathrm{C}$ and the lower limit is set to $25^{\circ} \mathrm{C}$. After inputting the upper and lower limit and the internal temperature is higher than the upper limit, the cooling fan becomes operated. If the internal temperature is lower than the lower limit, the Thermic ray becomes activated. If the internal temperature is between the upper and lower limits, the current temperature is maintained. 


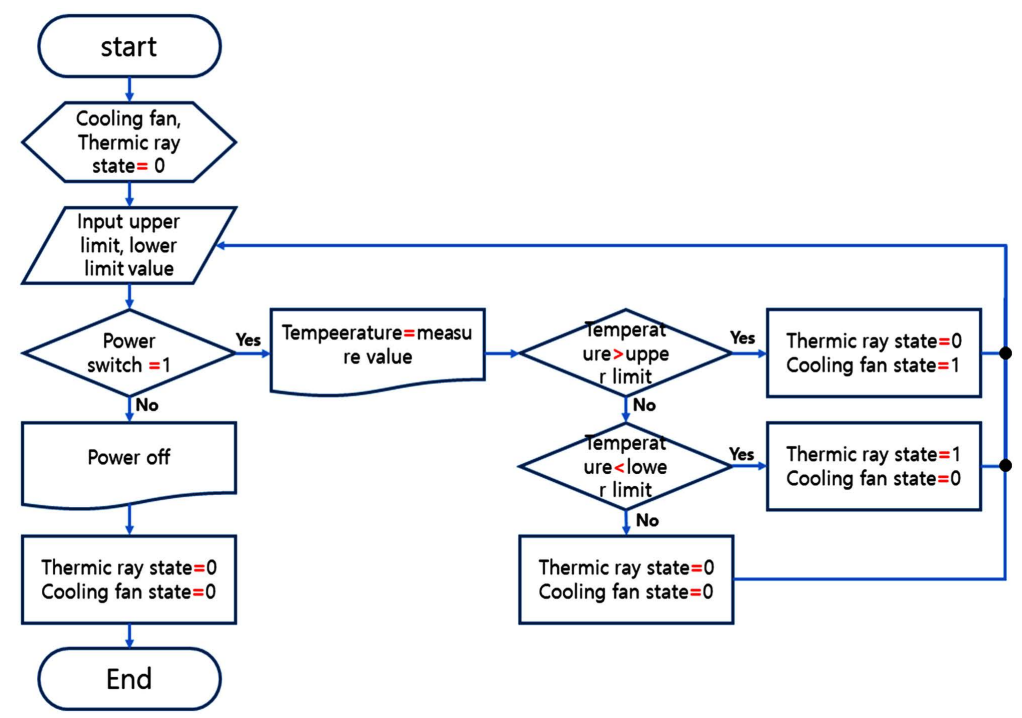

Figure 4. Temperature control algorithm pseudo code.

\section{Prototype Design}

Figure 5 shows the VTOL (vertical take-off and landing) drone equipped with a prototype temperature controlled cargo bay. Since the payload is about $2 \mathrm{~kg}$, the weight of the medical product as a transport item is considered. The cargo bay prototype was built with a weight of around $1.5 \mathrm{~kg}$. To check whether the temperature inside the cargo bay is controlled and maintained, two temperature sensors were used to measure the current temperature. The temperature inside the cargo bay was checked for 15 minutes in every 10 seconds. As shown in Figure 5, the upper and lower limits of the cargo bay temperature were adjusted to $25^{\circ} \mathrm{C}$ and $24^{\circ} \mathrm{C}$, respectively, and the cargo bay temperature was measured to be maintained at the desired setting.

It took about three minutes for the cargo bay internal temperature to reach the set point at $25.4^{\circ} \mathrm{C}$. After that, when the internal temperature is out of the set temperature, the cooling fan operates to maintain $25^{\circ} \mathrm{C}$. In order to check whether the temperature is maintained by thermic ray, it is verified by setting the cargo bay internal temperature to $26^{\circ} \mathrm{C}-27^{\circ} \mathrm{C}$, as shown in Figure 6. Compared to the cooling fan, the set temperature was reached in about 40 seconds. If the temperature goes out of the set temperature, the thermic ray is operated to increase the temperature to maintain the internal temperature, and there is an error of about $0.1^{\circ} \mathrm{C}$.

The controller can effectively recognizes and controls the setting measured by the temperature sensors. However, an error occurs between the set temperature and the holding temperature. The error in temperature is due to the delay in the data and must react immediately when the temperature changes. In fact, the precise measurement, control, and data processing require the use of high-performance computers, sensors, and devices. In this study, however, due to the limitations of weight and payload of the drone, the use of high performance precision device was not feasible (Table 4). 


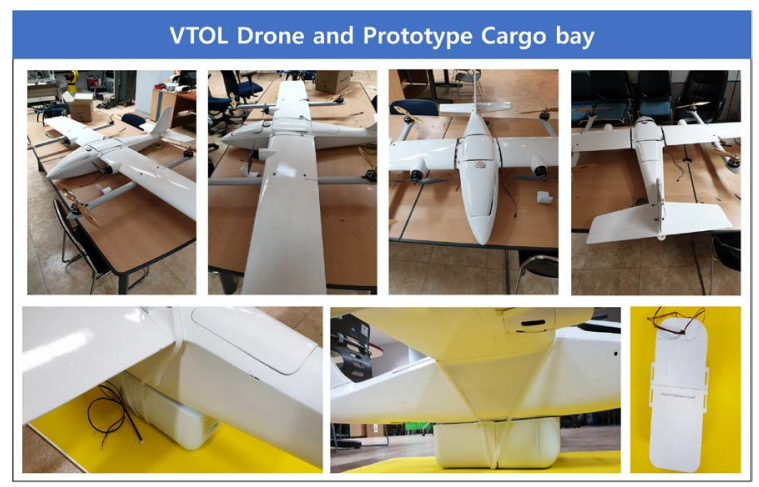

Figure 5. Temperature module prototype.

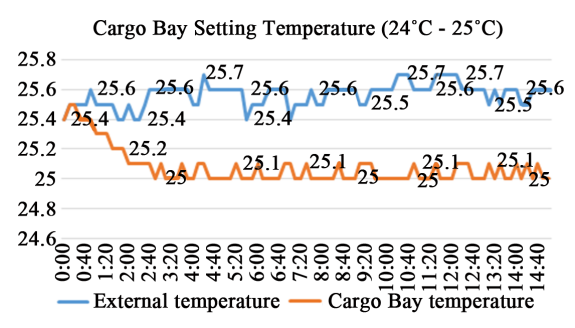

(a)

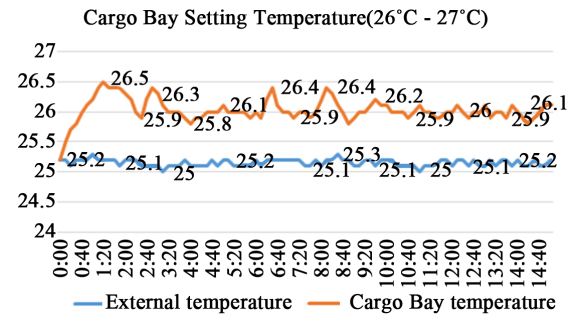

(b)

Figure 6. External temperature vs. cargo bay internal temperature. (a) Graph of internal temperature and external temperature; (b) Graph of internal temperature and external temperature.

Table 4. Erro value with a 40 second interval.

\begin{tabular}{|c|c|c|c|c|c|c|c|}
\hline${ }^{\circ} \mathrm{Ct}$ & $40(s)$ & $80(s)$ & $120(s)$ & $160(s)$ & $200(s)$ & $240(s)$ & $280(s)$ \\
\hline $24^{\circ} \mathrm{C}-25^{\circ} \mathrm{C}$ & \multicolumn{3}{|c|}{ Set temperature reach section } & $0.1^{\circ} \mathrm{C}$ & $0.1^{\circ} \mathrm{C}$ & $0.1^{\circ} \mathrm{C}$ & $0.1^{\circ} \mathrm{C}$ \\
\hline \multirow[t]{2}{*}{$26^{\circ} \mathrm{C}-27^{\circ} \mathrm{C}$} & \multicolumn{3}{|c|}{ Set temperature reach section } & $0.1^{\circ} \mathrm{C}$ & - & $0.2^{\circ} \mathrm{C}$ & - \\
\hline & $320(s)$ & $360(s)$ & $400(s)$ & $440(s)$ & $480(s)$ & $520(s)$ & $560(s)$ \\
\hline $24^{\circ} \mathrm{C}-25^{\circ} \mathrm{C}$ & $0.1^{\circ} \mathrm{C}$ & $0.1^{\circ} \mathrm{C}$ & $0.1^{\circ} \mathrm{C}$ & $0.1^{\circ} \mathrm{C}$ & - & $0.1^{\circ} \mathrm{C}$ & $0.1^{\circ} \mathrm{C}$ \\
\hline \multirow[t]{2}{*}{$26^{\circ} \mathrm{C}-27^{\circ} \mathrm{C}$} & - & $0.1^{\circ} \mathrm{C}$ & - & $0.1^{\circ} \mathrm{C}$ & - & $0.2^{\circ} \mathrm{C}$ & - \\
\hline & $600(s)$ & $640(s)$ & $680(s)$ & $720(s)$ & $760(s)$ & $800(s)$ & $840(s)$ \\
\hline $24^{\circ} \mathrm{C}-25^{\circ} \mathrm{C}$ & - & $0.1^{\circ} \mathrm{C}$ & $0.1^{\circ} \mathrm{C}$ & - & $0.1^{\circ} \mathrm{C}$ & $0.1^{\circ} \mathrm{C}$ & $0.1^{\circ} \mathrm{C}$ \\
\hline $26^{\circ} \mathrm{C}-27^{\circ} \mathrm{C}$ & - & $0.1^{\circ} \mathrm{C}$ & - & - & $0.1^{\circ} \mathrm{C}$ & $0.1^{\circ} \mathrm{C}$ & $0.2^{\circ} \mathrm{C}$ \\
\hline
\end{tabular}

The temperature measured for a total of 15 minutes, and the interval was set as 40 seconds. Each error value is an absolute value that is the maximum error. In order to reduce error from the data delay, there are ways to increase the electronic device load capacity by using the high performance computers, sensors and devices, or to increase the network performance of the controller. Also, there is a way to use the LTE modem to increase the controller and network performance. If a modem to make the controller an access point (AP) is used to reduce the data delay, one can effectively reduce the error [13]. 


\section{Conclusion}

This paper deals with the development of temperature controlled cargo bay to protect goods from decay due to external environmental factors. A small controller, Raspberry $\mathrm{Pi}$, was used to control the temperature control device, and a cloud server was used to solve the communication distance limitations. As a result of detecting the change of the cargo bay internal temperature for $15 \mathrm{mi}$ nutes, it was confirmed that the set temperature was effectively maintained and monitored, despite some small errors. The developed device can be used to protect and safely transport items that are easily corrupted and deteriorated, such as medical blood products that are very sensitive to outside temperature variations. Even though the proposed device showed a small range of errors during the operation, this problem can be easily solved by using more accurate devices. The method provides a new approach to either raising or lowering the inside temperature of drone cargo bay, and such can be done remotely in real-time. By doing so, the temperature variations during the flight can be verified, and the end user can be assured that the transport items have arrived safely.

\section{Acknowledgements}

This work was supported by the Hyundai-NGV Future Technology Research Fund.

\section{Conflicts of Interest}

The authors declare no conflicts of interest regarding the publication of this paper.

\section{References}

[1] Laksham, K.B. (2019) Unmanned Aerial Vehicle (Drones) in Public Health: A SWOT Analysis. Journal of Family Medicine and Primary Care, 8, 342-349. https://doi.org/10.4103/jfmpc.jfmpc $413 \quad 18$

[2] Griffiths, F. and Ooi, M. (2018) The Fourth Industrial Revolution-Industry 4.0 and IoT. IEEE Instrumentation \& Measurement Magazine, 21, 29-43. https://doi.org/10.1109/MIM.2018.8573590

[3] Li, B., Fei, Z. and Zhang, Y. (2019) UAV Communications for 5G and Beyond: Recent Advances and Future Trends. IEEE Internet of Things Journal, 6, 2241-2263. https://doi.org/10.1109/JIOT.2018.2887086

[4] Klinkmueller, K.M., Wieck, A.J., Holt, J.K. and Valentine, A.W. (2019) Airborne Delivery of Unmanned Aerial Vehicles via Joint Precision Airdrop Systems. AIAA Scitech 2019 Forum, San Diego, CA, 7-11 January 201, 2285. https://doi.org/10.2514/6.2019-2285

[5] Amukele, T., Ness, P.M., Tobian, A.R., Boyd, J. and Street, J. (2016) Drone Transportation of Blood Products. Transfusion, 57, 582-588. https://doi.org/10.1111/trf.13900

[6] Scott, J.E. and Scott, C.H. (2017) Drone Delivery Models for Healthcare. Proceedings of the 50 th Hawaii International Conference on System Sciences, Hilton Waikoloa Village, HI, 4-7 January 2017, 3297-3304. 
https://doi.org/10.24251/HICSS.2017.399

[7] Lee, J.H. (2017) Optimization of a Modular Drone Delivery System. 2017 IEEE International Systems Conference, Montreal, 24-27 April 2017, 1-8.

[8] Erdos. D., Erdos. A. and Watkins, S.E. (2013) An Experimental UAV System for Search and Rescue Challenge. IEEE Aerospace and Electronic Systems Magazine, 28. 32-37. https://doi.org/10.1109/MAES.2013.6516147

[9] Xiang, G., Hardy, A., Rajeh, M. and Venuthurupalli, L. (2016) Design of the Life-Ring Drone Delivery System for Rip Current Rescue. 2016 IEEE Systems and Information Engineering Design Symposium, Charlottesville, VA, 29April 2016, 181-186. https://doi.org/10.1109/SIEDS.2016.7489295

[10] https://www.hankookilbo.com/News/Read/201903201101062687

[11] https://fortune.com/2019/01/07/delivery-drones-rwanda/

[12] Lee, S.-H., Yang, S.-H. and You, Y.-M. (2017) Design and Development of Agriculture Drone Battery Usage Monitoring System Using Wireless Sensor Network. The International Journal of Advanced Smart Convergence, 6, 38-44.

[13] Krishna Chand, G.S.L., Lee, M. and Shin, S.Y. (2018) Drone Based Wireless Mesh Network for Disaster/Military Environment. Journal of Computer and Communications, 6, 44-52. https://doi.org/10.4236/jcc.2018.64004 